\title{
Association of apolipoprotein B Xbal (rs693) polymorphism and gallstone disease risk based on a comprehensive analysis
}

\author{
Haifeng Zhu, Linhai Yu and Linsong Feng
}

\begin{abstract}
Background: Our aim was to investigate the association between Xbal gene polymorphisms in the apolipoprotein $\mathrm{B}(A P O B)$ gene and gallstone disease (GD) risk through a comparison of the allele and genotype distribution frequencies at this site using meta-analysis.

Methods: A literature search was performed using PubMed and Wanfang through Jun 1, 2020. Odds ratios (ORs) and $95 \%$ confidence intervals (Cls) were used to assess the strength of associations.

Results: After a comprehensive search, 14 different articles that met the inclusion criteria were selected, with 1583 cases and 1794 controls. Individuals carrying the A-allele or AA genotype of the rs693 polymorphism were determined to possibly have an increased risk of GD. For example, there was a significant relationship between the rs693 polymorphism and increased GD risk in the whole group (OR: 1.40, $95 \% \mathrm{Cl}: 1.05-1.87$ in the allelic contrast model), the Asian population (OR: 1.58, $95 \%$ Cl: 1.48-2.84 in the heterozygote model), and the hospital-based source of the control (OR: 1.79, $95 \%$ Cl: 1.13-2.84 in the dominant model).
\end{abstract}

Conclusions: This study suggests that the APOB rs693 polymorphism is potentially associated with GD susceptibility, which might offer a detection marker for use in future large scale clinic research.

Keywords: Apolipoprotein B, Gallstone disease, Polymorphism, Meta-analysis, Risk

\section{Background}

Gallbladder disease (GD) is a highly prevalent condition affecting up to $15 \%$ of the population with a significant health care burden in the United States [1-3]. Approximately $10-20 \%$ of the population will develop GD in their lifetime [4], and women are more than twice as likely as men to develop the disease [5]. Based on current information using ultrasound surveys, ethnicity is a known risk factor; specifically, the highest rate of GD is found in Hispanic people from central and south American heritage $[2,3]$. The north Indian population also shows a high incidence of GD, affecting $64.1 \%$

\footnotetext{
* Correspondence: doctorfls@163.com

Department of Surgery, Fangta Hospital of Traditional Chinese Medicine,

Songjiang District, 201600 Shanghai, China
}

women and $29.5 \%$ men [2]. On the other hand, individuals of African American, African, and East-South Asian (China, Japan, India, and Thailand) descent show lower incidence of GD development [6].

Besides race, there are many other factors for GD development, such as advanced age, sex, and a hypercaloric diet rich in carbohydrates and poor in fiber. Additionally, obesity is one of the most important predisposing factor for GD. Other factors that affect the hepatic production of cholesterol, stasis/inflammation, bile acid production, or intestinal absorption of cholesterol and bile acids also contribute to GD development. Increasing evidence also points to genetic factors as being important for GD development $[4,7]$.

C C The Author(s). 2021 Open Access This article is licensed under a Creative Commons Attribution 4.0 International License, which permits use, sharing, adaptation, distribution and reproduction in any medium or format, as long as you give appropriate credit to the original author(s) and the source, provide a link to the Creative Commons licence, and indicate if changes were made. The images or other third party material in this article are included in the article's Creative Commons. licence, unless indicated otherwise in a credit line to the material. If material is not included in the article's Creative Commons licence and your intended use is not permitted by statutory regulation or exceeds the permitted use, you will need to obtain permission directly from the copyright holder. To view a copy of this licence, visit http://creativecommons.org/licenses/by/4.0/ The Creative Commons Public Domain Dedication waiver (http://creativecommons.org/publicdomain/zero/1.0/) applies to the data made available in this article, unless otherwise stated in a credit line to the data. 
The apolipoprotein $\mathrm{B}(A P O B)$ gene, presumably affecting the lipid composition and lipid metabolism $[8,9]$, plays an important role in GD development. The XbaI polymorphism site (rs693) is located in exon 26 of the $A P O B$ gene $[10,11]$, which is a synonymous variant. It is well known that synonymous single-nucleotide polymorphisms (SNPs) are categorized as spurious events under no to modest selection through alterations to a nucleotide at a synonymous codon but retaining the encoded amino acid [12]. Synonymous SNPs are not randomly distributed across genes and preferentially target conserved sites [13]. In addition, synonymous mutations, which account for a larger proportion of somatic mutations detected in human pathology, play an important role in disease penetrance and are presumed to be driving mutations in some diseases [14], such as GD. The relationship between this polymorphism and GD has been examined in several studies; however, the conclusions have been unclear [15-28].

In a previous study, Niu et al. performed a metaanalysis and suggested that the rs693 polymorphism is significantly associated with higher levels of APOB, triglycerides (TG), total cholesterol (TC), and low-density lipoprotein cholesterol (LDL-C). Our current study comprised a similar meta-analysis, because GD is associated with the metabolism of TG, TC, and LDL-C [29]. To overcome factors such as sample size and regional and ethnic differences, our study summarized all published literature on the relationship between the XbaI polymorphism and GD based on meta-analysis, to comprehensively evaluate this relationship and provide an evidence-based medical basis for the etiology of GD.

\section{Materials and methods}

\section{Literature search strategy}

A computerized literature search was performed for relevant studies from PubMed and Wanfang published before Jun 1, 2020. The following keywords were jointly used: "Apolipoprotein B or $A P O B$ or Apo B," "polymorphism or variation or mutation," "rs693," and "gallstone or cholelithiasis or biliary stone or bile duct stone." If studies applied the same clinical case information, only the largest sample size was selected.

\section{Inclusion criteria}

The included studies met the following criteria: (a) clear criteria for the diagnosis of GD, such as B-ultrasound, CT, MRI, or endoscopic retrograde cholangiopancreatography, among others; (b) a correlation between GD risk and $A P O B$ gene rs693 polymorphism; (c) case-control or cohort design; (d) providing sufficient data for calculating the odds ratio (OR) with a $95 \%$ confidence interval (CI); (e) duplicate studies with the same cases; (f) the genotype distribution in the control group was in accordance with the Hardy-Weinberg equilibrium (HWE) law.

\section{Data extraction}

The following information was extracted from each included study: name of the first author, publication year, country of origin, ethnicity, numbers of cases and controls, HWE of control group, genotyping method, and number of genotypes in cases and controls. The data were selected independently by two investigators who reached a consensus on all items.

\section{Statistical analysis}

The associations between the $A P O B$ rs693 polymorphism and risk of GD were estimated by calculating the OR and $95 \%$ CI. The statistical significance of the OR [30] and the significance of the effect for the correlation were determined using $\mathrm{Z}$ test. The heterogeneity among studies was evaluated using $\mathrm{Q}$ test and $I^{2}$ test as described previously $[31,32]$. As a guide, $I^{2}$ values $<25 \%$ might be considered "low," a value of $~ 50 \%$ might be considered "moderate," and values $>75 \%$ might be considered "high" [33]. The Mantel-Haenszel (fixed effect) model was chosen, and otherwise, if $P_{\text {heterogeneity }}<0.1$, the random effects (DerSimonian-Laird) model was applied $[34,35]$. Sensitivity analysis was undertaken by removing each study once to assess whether any single study could influence the stability of results [36]. The departure of frequencies of the rs11200638 polymorphism from expectation under the HWE was assessed using Pearson's $X^{2}$ test, and $P<0.05$ was considered significant [37]. Begg's funnel plots and Egger's regression test were performed to estimate the potential publication bias [38]. All statistical tests for this meta-analysis were performed using the Stata software, version 10.0 (StataCorp LP, College Station, TX, USA).

\section{Meta-regression}

Considering the subgroups of publication year, ethnicity, source of control as independent variables, and the log as a dependent variable, the random-effect metaregression results were presented.

\section{Protein-interaction network of the $A P O B$ gene}

To more completely understand the role of APOB in GD, the gene-gene interaction network for $A P O B$ was predicted using the online String database (http://string-db.org/) [39].

\section{Results}

Study search and basic information

As depicted in Fig. 1 and 58 articles were gathered from PubMed (44 titles) and Wanfang (14 titles) databases. Moreover, 33 obviously irrelevant articles were excluded after screening the titles and abstract sections. The full 


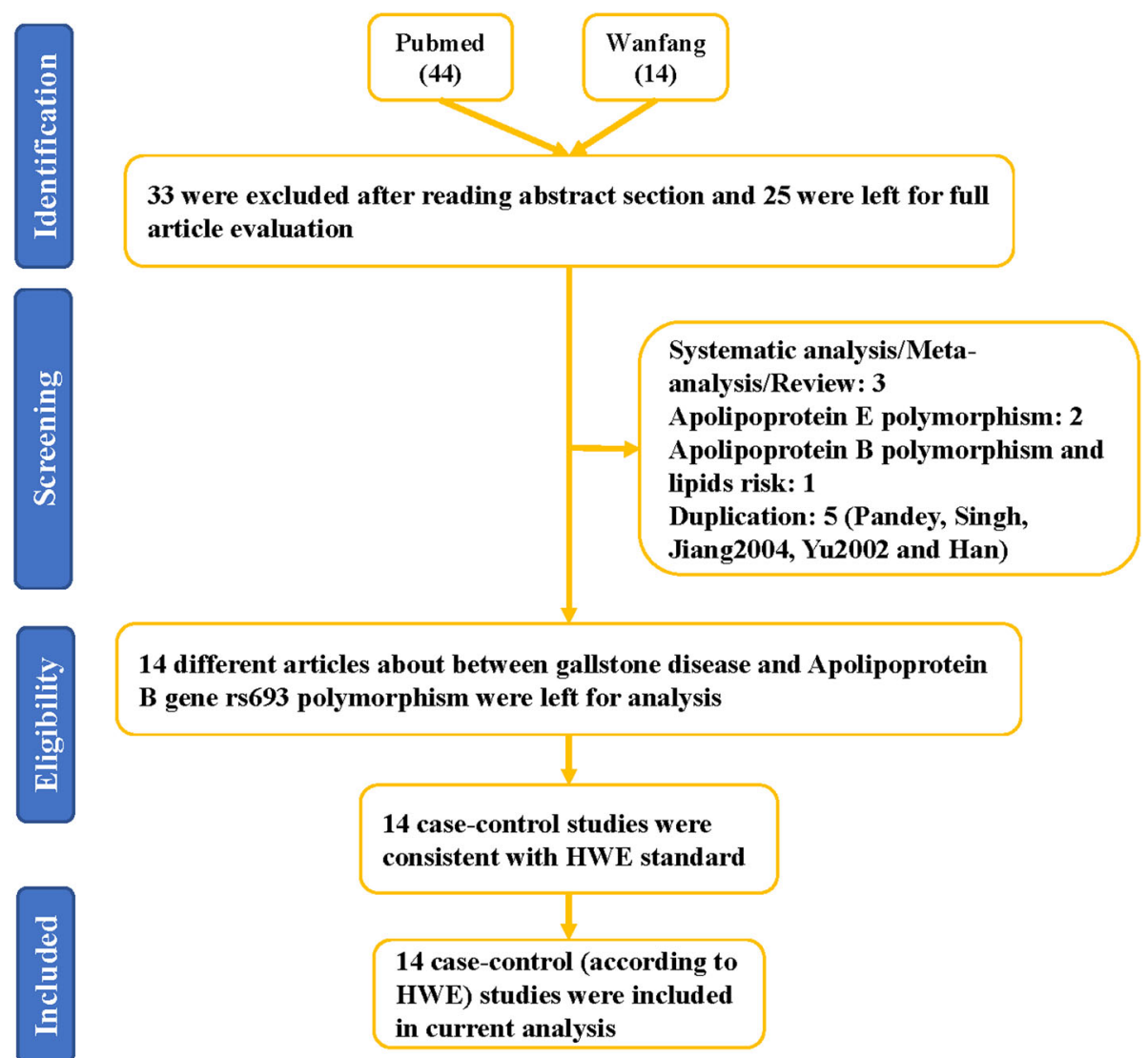

Fig. 1 Flowchart illustrating the search strategy used to identify association studies for $A P O B$ gene rs693 polymorphisms and GD risk

texts were then evaluated, and 11 additional articles were further excluded as they were duplications (5); a meta-analysis, systematic analysis, or review (2); considered other gene polymorphisms (3); and associated with the risk of another disease (1). Finally, 14 different articles [15-28] met the inclusion criteria and were included in our meta-analysis. Among these, eight were performed in China, two in Poland, one in India, one in the UK, and one in Japan. All included studies used blood samples for DNA extraction. In addition, all case-control studies about the rs693 polymorphism were consistent with the HWE in control groups (Table 1). In addition, we checked the minor allele frequency reported for the six main worldwide populations in the 1000 Genomes Browser (https://www.ncbi.nlm.nih.gov/snp/rs693) as follows: global (0.251); Europe (0.4423); East Asian (0.0615); South Asian (0.216); African (0.2095); American (0.378) (Fig. 2). In addition, we tested this polymorphism with respect to whether it influences the expression of APOB by analyzing different genotypes based on the GTEx Portal (https://www.gtexportal.org/ home/). We found individuals carrying the AA genotype had higher APOB expression; however, it was determined that GG genotype-carriers might have lower expression of APOB (Fig. 3). The genotyping methods included polymerase chain reaction-restrictive fragment length polymorphism, sequencing, and TaqMan. Finally, we evaluated whether the rs693 polymorphism can influence $A P O B$ gene expression, and an online analysis service (https://www.gtexportal.org/home/) was applied. Results implied that individuals carrying the AA genotype might have higher $\mathrm{APOB}$ expression than those with the GG genotype, which suggested that the rs693 polymorphism can result in a change to the APOB protein and its functions.

\section{Quantitative synthesis}

In the entire analysis, increased associations were observed in the three genetic models (allelic contrast: OR: 1.40, $95 \%$ CI: $1.05-1.87, P_{\text {heterogeneity }}<0.001, P=0.023, I^{2}=73.9 \%$; heterozygote comparison: OR: $1.58,95 \%$ CI: $1.13-2.21, P_{\text {he- }}$ terogeneity $<0.001, P=0.007, I^{2}=67.8 \%$; dominant model: OR: $1.54,95 \%$ CI: $1.09-2.17, P<0.001$ for heterogeneity, $\left.P=0.014, I^{2}=71.1 \%\right)$. In subgroup analysis by ethnicity, based on different frequencies of races, there were also increased associations between this polymorphism and GD in Asians, but not in Europeans, in all models (A-allele vs. Gallele: OR: 1.94, $95 \%$ CI: $1.27-2.95, P_{\text {heterogeneity }}<0.001$, 
Table 1 Characteristics of included studies in $A P O B$ rs693 polymorphism and gallstone disease risk

\begin{tabular}{|c|c|c|c|c|c|c|c|c|c|c|c|c|c|c|c|}
\hline \multirow[t]{2}{*}{ Author } & \multirow[t]{2}{*}{ Year } & \multirow[t]{2}{*}{ Country } & \multirow[t]{2}{*}{ Ethnicity } & \multirow{2}{*}{$\begin{array}{l}\text { Sex } \\
\text { subgroup }\end{array}$} & \multirow[t]{2}{*}{ Case } & \multirow[t]{2}{*}{ Control } & \multicolumn{3}{|c|}{ Case } & \multicolumn{3}{|c|}{ Control } & \multirow[t]{2}{*}{ SOC } & \multirow[t]{2}{*}{ HWE } & \multirow[t]{2}{*}{ Genotype } \\
\hline & & & & & & & $A A$ & AG & GG & $\mathrm{AA}$ & AG & GG & & & \\
\hline Dixit [16] & 2008 & India & Asian & & 206 & 320 & 6 & 83 & 117 & 16 & 127 & 177 & $\mathrm{~PB}$ & 0.261 & $\overline{\text { sequence }}$ \\
\hline Juvonen [17] & 1995 & UK & Caucasian & & 76 & 92 & 9 & 27 & 40 & 15 & 42 & 35 & $\mathrm{HB}$ & 0.689 & PCR-RFLP \\
\hline Kurzawski [18] & 2007 & Poland & Caucasian & & 240 & 217 & 48 & 129 & 63 & 34 & 122 & 61 & PB & 0.076 & PCR-RFLP \\
\hline Rudzińska [19] & 2015 & Poland & Caucasian & & 59 & 58 & 12 & 30 & 17 & 12 & 31 & 15 & $\mathrm{HB}$ & 0.584 & PCR-RFLP \\
\hline Báez [15] & 2010 & Japan & Asian & & 119 & 70 & 13 & 65 & 41 & 14 & 31 & 25 & $\mathrm{HB}$ & 0.442 & Taqman \\
\hline Sánchez-Cuén [20] & 2010 & México & Caucasian & & 101 & 101 & 9 & 51 & 41 & 17 & 50 & 34 & PB & 0.848 & PCR-RFLP \\
\hline Jiang [23] & 1999 & China & Asian & & 189 & 442 & 0 & 39 & 150 & 0 & 35 & 407 & PB & 0.386 & PCR-RFLP \\
\hline Ji [22] & 2014 & China & Asian & & 55 & 65 & 0 & 3 & 52 & 0 & 2 & 63 & $\mathrm{HB}$ & 0.899 & PCR-RFLP \\
\hline $\mathrm{Gu}$ & 2006 & China & Asian & & 75 & 112 & 0 & 14 & 61 & 0 & 8 & 104 & $\mathrm{HB}$ & 0.659 & PCR-RFLP \\
\hline $\operatorname{Tan}[25]$ & 2003 & China & Asian & & 106 & 105 & 0 & 22 & 84 & 0 & 11 & 94 & PB & 0.571 & PCR-RFLP \\
\hline Yu [28] & 2005 & China & Asian & & 70 & 43 & 0 & 20 & 50 & 0 & 5 & 38 & $\mathrm{HB}$ & 0.685 & PCR-RFLP \\
\hline Suo [24] & 1999 & China & Asian & & 101 & 50 & 0 & 24 & 77 & 0 & 4 & 46 & $\mathrm{HB}$ & 0.768 & PCR-RFLP \\
\hline Wei [26] & 2001 & China & Asian & & 106 & 64 & 1 & 25 & 80 & 0 & 6 & 58 & $\mathrm{HB}$ & 0.693 & PCR-RFLP \\
\hline Yang [27] & 2009 & China & Asian & & 80 & 55 & 0 & 25 & 55 & 0 & 7 & 48 & $\mathrm{HB}$ & 0.614 & PCR-RFLP \\
\hline \multicolumn{16}{|l|}{ Sex subgroup } \\
\hline Dixit [16] & 2008 & India & Asian & Male & 64 & 115 & 3 & 24 & 37 & 7 & 46 & 62 & & & \\
\hline Dixit [16] & 2008 & India & Asian & Female & 142 & 205 & 3 & 59 & 80 & 9 & 81 & 115 & & & \\
\hline Rudzińska [19] & 2015 & Poland & Caucasian & Female & 59 & 58 & 12 & 30 & 17 & 12 & 31 & 15 & & & \\
\hline Wei [26] & 2001 & China & Asian & Male & 37 & 27 & 1 & 10 & 26 & 0 & 3 & 24 & & & \\
\hline Wei [26] & 2001 & China & Asian & Female & 69 & 37 & 0 & 15 & 54 & 0 & 3 & 34 & & & \\
\hline Jiang [23] & 1999 & China & Asian & Male & 114 & 299 & 0 & 19 & 95 & 0 & 24 & 275 & & & \\
\hline Jiang [23] & 1999 & China & Asian & Female & 75 & 143 & 0 & 20 & 55 & 0 & 11 & 132 & & & \\
\hline
\end{tabular}

$P=0.002, I^{2}=73.7 \%$, Fig. 4 A; AG vs. GG: $\mathrm{OR}=2.18$, $95 \% \mathrm{CI}=1.48-3.21, P_{\text {heterogeneity }}=0.008, \mathrm{P}<0.001, I^{2}=$ 59.3.9\%, Fig. 4 C; AA + AG vs. GG: OR: $2.41,95 \%$ CI: $1.41-3.24, \quad P_{\text {heterogeneity }}=0.002, P<0.001, \quad I^{2}=65.8 \%$, Fig. 4E). In addition, regular analysis with source of control also showed a significant trend for this SNP in HB rather than PB studies (such as A-allele vs. G-allele: OR: 1.63, $95 \%$ CI: $1.07-2.49, P_{\text {heterogeneity }}<0.001, P=0.023, I^{2}=$

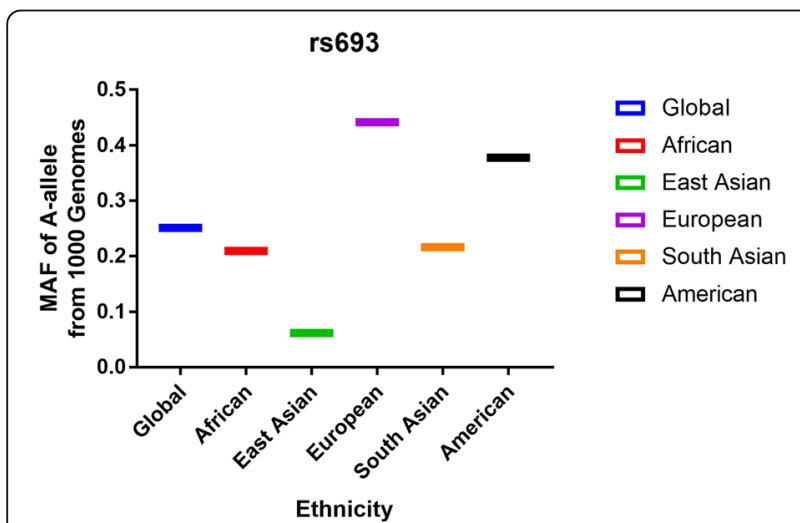

Fig. 2 The MAF of minor-allele (mutant-allele) for APOB gene rs693 polymorphism from the 1000 Genomes online database and present analysis

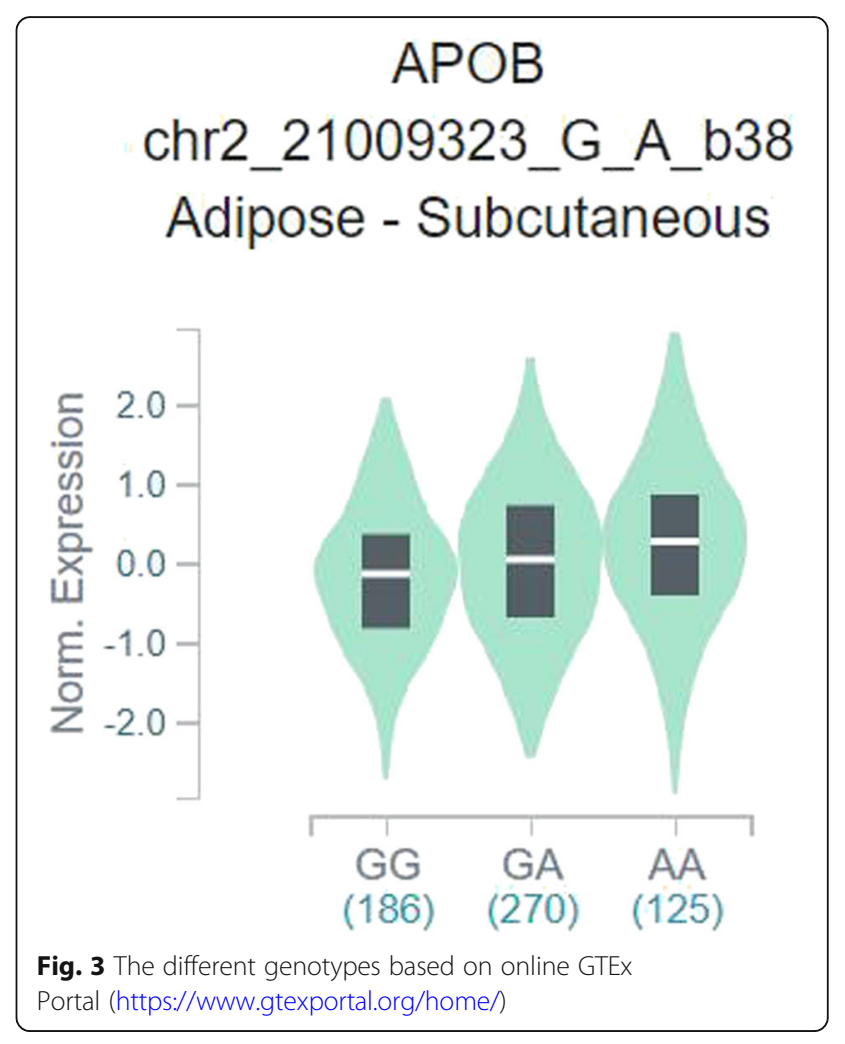




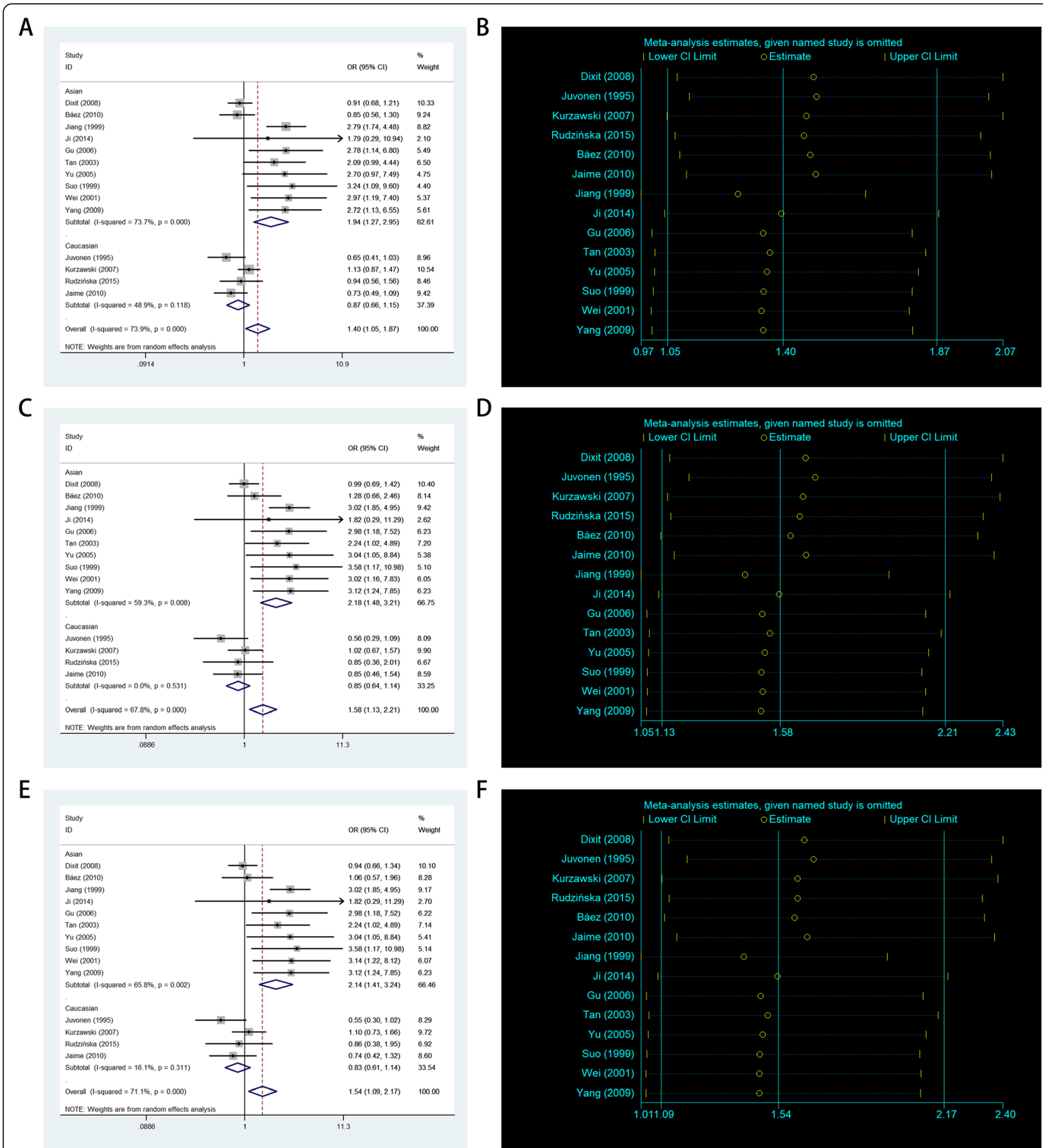

Fig. 4 A-allele frequencies for the $A P O B$ gene rs693 polymorphism among cases/controls stratified by ethnicity. a A-allele vs. G-allele model; c AG vs. GG model; e AA + AG vs. GG model. Sensitivity analysis between APOB gene rs693 polymorphism and GD risk. b A-allele vs. G-allele model; d AG vs. GG model; f AA + AG vs. GG model

$70.0 \%)$. Finally, different sexes had a different incidence, and we tried to analyze this relationship in the sex subgroup as to whether significant associations exist in our analysis, but unfortunately, no significant association was found both for males and females in the three models (Fig. 5 A-C; Table 2).
Bias diagnosis for publication and sensitivity analysis

The publication bias was evaluated by using both Begg's funnel plot and Egger's test. At the beginning, the shape of the funnel plots seemed asymmetrical for the allele comparison of rs693 obtained using Begg's test, suggesting that no publication bias existed. Then, Egger's test 
was applied to provide statistical evidence of funnel plot symmetry. As a result, no obvious evidence of publication bias was observed (A-allele vs. G-allele: $\mathrm{t}=2.57, P=$ 0.024 for Egger's test; $\mathrm{z}=1.75, P=0.08$ for Begg's test; Fig. 6 A,B; Table 3). To exclude studies that might influence the power and stability of the entire study, we applied sensitivity analysis; finally, no sensitive case-control studies were found for this SNP in the three models (Fig. 4B,D,F).

\section{Meta-regression}

This analysis showed only a significant relationship for the allele model (A-allele vs. G-allele) for ethnicity with a regression coefficient of 0.006 , rather than for the publication year and source of control subgroups, which means that the heterogeneity of the rs693 polymorphism in $\mathrm{AF}$ might be from the subgroup of ethnicity (Fig. 7 A-F).

\section{Gene-gene Network Diagram and interaction based on} Online Website

The String online server indicated that the $A P O B$ gene interacts with numerous genes. The gene-gene interaction network has been illustrated in Fig. 8 .

\section{Discussion}

GD is the most common disorder of the biliary system worldwide. The disease is generally non-life-threatening; however, the quality of life for patients is affected by upper right abdominal pain with an increased incidence of nausea, vomiting, and feelings of fullness after meals [40]. The incidence of GD has increased rapidly by nearly 2 -fold every 10 years based on diet changes, widespread type-B ultrasound application, the concept of physical examinations, and other factors. Hence, further exploration of potential risk factors (besides common factors, such as pregnancy, obesity, metabolic syndrome, bariatric surgery, and ileal resection [41]) of GD should

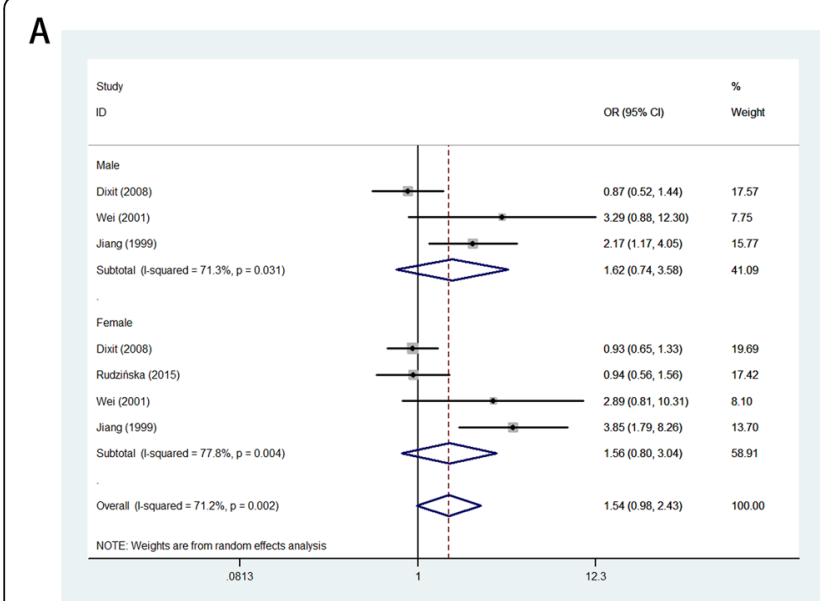

B

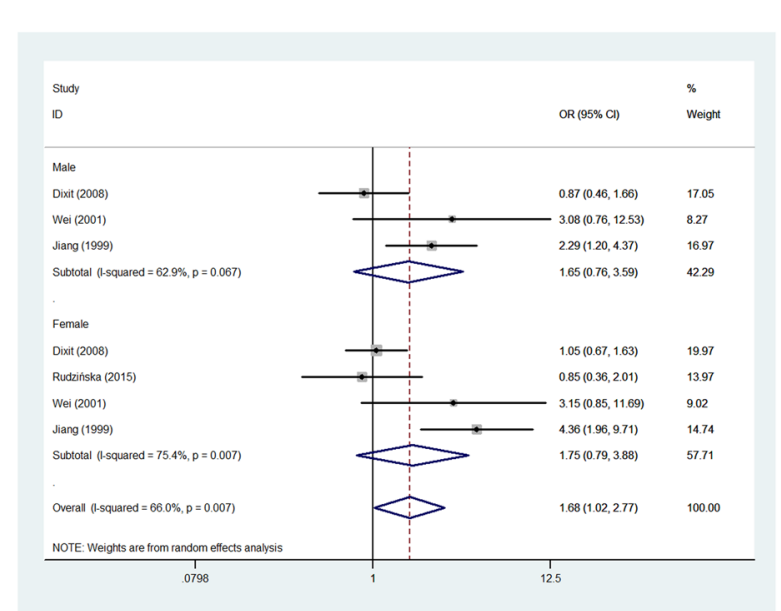

C

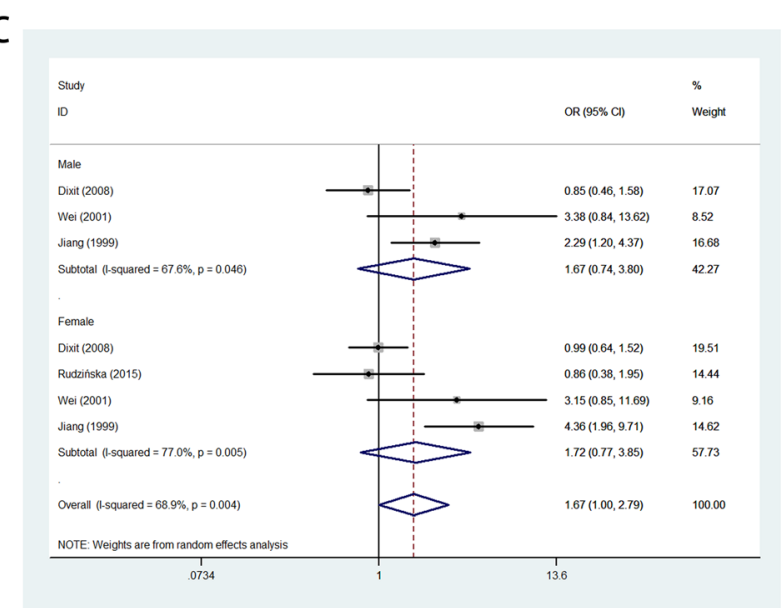

Fig. 5 Forest plot of GD risk associated with $A P O B$ gene rs693 polymorphism by sex subgroup. a A-allele vs. G-allele model; c AG vs. GG model; e $A A+A G$ vs. GG model 
Table 2 Results of the meta-analysis on APOB rs693 polymorphism and gallstone disease risk in total and types of subgroups

\begin{tabular}{|c|c|c|c|c|c|}
\hline Variables & $\mathbf{N}$ & $\begin{array}{l}\text { Case/ } \\
\text { Control }\end{array}$ & $\begin{array}{l}\text { Allelic contrast } \\
\text { OR(95\%Cl) } P_{\mathrm{h}} P \text { I-squared }\end{array}$ & $\begin{array}{l}\text { Heterozygote comparison } \\
\text { OR(95\%Cl) } P_{\mathrm{h}} P \text { I-squared }\end{array}$ & $\begin{array}{l}\text { Dominant model } \\
\text { OR(95\%Cl) } P_{\mathrm{h}} P \text { I-squared }\end{array}$ \\
\hline Total & 14 & $1583 / 1794$ & $1.40(1.05-1.87) 0.0000 .02373 .9 \%$ & $1.58(1.13-2.21) 0.0000 .00767 .8 \%$ & $1.54(1.09-2.17) 0.0000 .01471 .1 \%$ \\
\hline \multicolumn{6}{|l|}{ Ethnicity } \\
\hline Asian & 10 & $1107 / 1326$ & $1.94(1.27-2.95) 0.0000 .00273 .7 \%$ & $2.18(1.48-3.21) 0.0080 .00059 .3 \%$ & $2.14(1.41-3.24) 0.0020 .00065 .8 \%$ \\
\hline European & 4 & $476 / 468$ & $0.92(0.77-1.11) 0.1180 .38248 .9 \%$ & $0.85(0.64-1.14) 0.5310 .2850 .0 \%$ & $0.85(0.64-1.12) 0.3110 .24316 .1 \%$ \\
\hline China & 8 & $782 / 936$ & $2.68(2.01-3.58) 0.9970 .0000 .0 \&$ & $2.90(2.15-3.92) 0.9970 .0000 .0 \%$ & $2.92(2.16-3.94) 0.9960 .0000 .0 \%$ \\
\hline Not-China & 6 & $801 / 858$ & $0.91(0.79-1.05) 0.3070 .20016 .5 \%$ & $0.94(0.76-1.16) 0.6170 .5570 .0 \%$ & $0.90(0.73-1.11) 0.5400 .3150 .0 \%$ \\
\hline \multicolumn{6}{|l|}{ SOC } \\
\hline$H B$ & 9 & $741 / 609$ & $1.63(1.07-2.49) 0.0000 .02370 .0 \%$ & $1.83(1.18-2.84) 0.0090 .00759 .1 \%$ & $1.79(1.13-2.84) 0.0020 .01464 .9 \%$ \\
\hline PB & 5 & $842 / 1185$ & $1.28(0.84-1.94) 0.0000 .25682 .9 \%$ & $1.39(0.85-2.25) 0.0010 .18778 .3 \%$ & $1.35(0.82-2.23) 0.0000 .23280 .5 \%$ \\
\hline \multicolumn{6}{|c|}{ Sex subgroup } \\
\hline Male & 3 & $215 / 441$ & $1.62(0.74-3.58) 0.0310 .23171 .3 \%$ & $1.65(0.76-3.59) 0.0670 .20862 .9 \%$ & $1.67(0.74-3.80) 0.0460 .21967 .6 \%$ \\
\hline Female & 4 & $345 / 443$ & $1.56(0.80-3.04) 0.0040 .19277 .8 \%$ & $1.75(0.79-3.88) 0.0070 .16775 .4 \%$ & $1.72(0.77-3.85) 0.0050 .18877 .0 \%$ \\
\hline
\end{tabular}

$P_{\mathrm{h}}$ : value of $Q$-test for heterogeneity test; $P$ : Z-test for the statistical significance of the $\mathrm{OR}$

be conducted. $\mathrm{Gu}$ et al. carried out an observational study, suggesting that alanine transaminase activity, total standard bicarbonate, TG, and low density lipoprotein levels might be associated with the risk of GD [42].

To date, multiple genes have been shown to be associated with increased GD risk, such as ATP binding cassette subfamily $\mathrm{G}$ member 8 , mucin-like protocadherin, and apolipoprotein E [43-45]. In addition, more and more studies have indicated that the $A P O B$ rs693 polymorphism might be associated with GD risk. Due to the limited number of samples used for each study, the conclusion for every study might not be credible. Dixit et al. included 214 patients with GD and 322 healthy controls and suggested that the rs693 polymorphism might not be related to GD risk[16]. In addition, Baez et al. enrolled 110 patients with GD and 70 healthy controls and showed that the rs693 variant is involved in gallstone formation and GD risk[15]. It is necessary to combine all previous studies and increase the sample size, and our aim was to obtain a comprehensive and convincing conclusion about the association between the rs693 polymorphism and GD susceptibility.

Thus, it was necessary to analyze the association between the rs693 polymorphism and GD risk using a meta-analysis method. After searching through the main database, 14 different case-control studies were identified, including 1583 cases of GD and 1794 controls. The main result of the current study is that the rs693 polymorphism is a risk factor for GD for all patients, especially in the Asian population (Chinese), which might offer a reference for early detection, prevention, and treatment. Because the incidence for GD between males and females is different, we tried to analyze whether the rs693 polymorphism differed between the two sexes; however, the analysis did not produce any positive results, which might be due to the samples.
We found publication bias in the A-allele vs. G-allele model, which might affect the strength and credibility of our conclusion. Here, we have discussed some possible reasons for this. According to the composition of the GD, it can be categorized as follows: cholesterol stones, pigment stones, and mixed stones, of which cholesterol stones are the most common; and based on the site of occurrence, GD can be divided into extrahepatic bile duct stones and hepatolithiasis, of which gallstones account for approximately $50 \%$ of all stones. In the studies included presently, only one study indicated cholesterol stone; meta-regression was applied and showed heterogeneity. Moreover, publication bias might originate from ethnicity, because most studies were from Asian populations, especially from China, and only two studies were from Europe.

It is well known that the development of GD is complex and multi-factorial. Focusing on only one gene or one polymorphism might create a bias. Thus, we attempted to detect some related genes associated with $A P O B$ based on the online String server. The 10 most probable genes are shown in the network around the $A P O B$ gene. Among them, six are of the apolipoprotein family (subtypes), and the first related genes are $A P O A 1$ and APOA2. Dixit et al. confirmed that the APOA1 75G/ A polymorphism is associated with GD and showed sexspecific differences. However, the APOC3 Sstl polymorphism was not found to be a factor for GD susceptibility [46]. Sarac et al. reported that increased leptin levels are associated with high LPA and APOB levels; however, in contrast, decreased APOA1 levels are found in patients with cholelithiasis [47]. Li et al. conducted meta-analyses and found insufficient evidence of an association between the APOE E4 polymorphism and GD risk [45]. Castro et al. suggested increased hepatic 

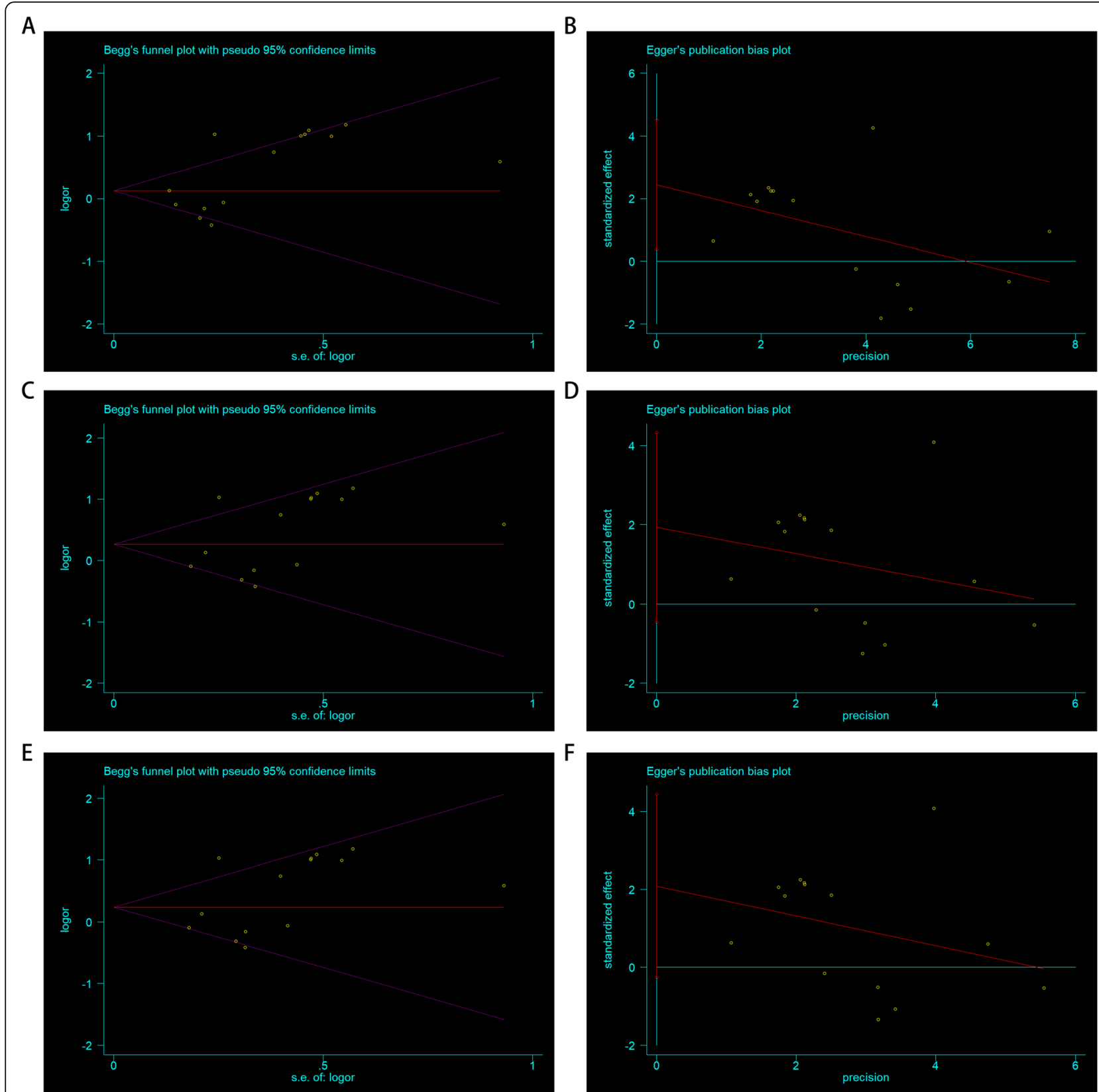

Fig. 6 Begg's funnel plot for publication bias test. a A-allele vs. G-allele model; c AG vs. GG model; e AA + AG vs. GG model. Each point represents a separate study for the indicated association. Log $[O R]$, natural logarithm of OR. Horizontal line, mean effect size. Egger's publication bias plot. b A-allele vs. G-allele model; d AG vs. GG model; f AA + AG vs. GG model

Table 3 Publication bias tests (Begg's funnel plot and Egger's test for publication bias test) for APOB rs693 polymorphism

\begin{tabular}{llllllll}
\hline $\begin{array}{l}\text { Egger's test } \\
\text { Genetic type }\end{array}$ & Coefficient & $\begin{array}{l}\text { Standard } \\
\text { error }\end{array}$ & $\mathbf{t}$ & $\begin{array}{l}\boldsymbol{P} \\
\text { value }\end{array}$ & $\begin{array}{l}\mathbf{9 5} \% \mathrm{Cl} \text { of } \\
\text { intercept }\end{array}$ & $\begin{array}{l}\text { Begg's test } \\
\mathbf{z}\end{array}$ & $\begin{array}{l}\boldsymbol{P} \\
\text { value }\end{array}$ \\
\hline A-allele vs. G-allele & 2.445 & 0.949 & 2.57 & 0.024 & $(0.375-4.514)$ & 1.75 & 0.08 \\
AG vs. GG & 1.932 & 1.100 & 1.76 & 0.104 & $(-0.464-4.329)$ & 1.75 & 0.08 \\
AA + AG vs. GG & 2.087 & 1.080 & 1.93 & 0.077 & $(-0.266-4.441)$ & 1.75 & 0.08 \\
\hline
\end{tabular}




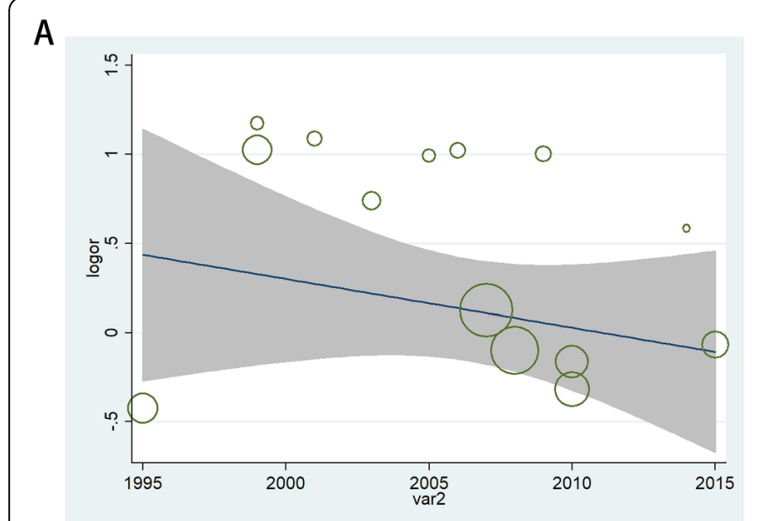

B

Meta-regression

REML estimate of between-study variance

Number of obs $=14$

$\%$ residual variation due to heterogeneity

tau2 $=.2671$

proportion of between-study variance explained

I-squared_res $=73.70 \%$

with Knapp-Hartung modification

Adj R-squared $=-0.42 \%$

\begin{tabular}{r|rrrrrr}
\hline logor & Coef. & Std. Err. & $t$ & $p\rangle|t|$ & [95\% Conf. Interval] \\
\hline var2 & -.0302314 & .0298559 & -1.01 & 0.331 & -.0952819 & .0348191 \\
- cons & 60.99667 & 59.88216 & 1.02 & 0.328 & -69.47534 & 191.4687 \\
\hline
\end{tabular}

C

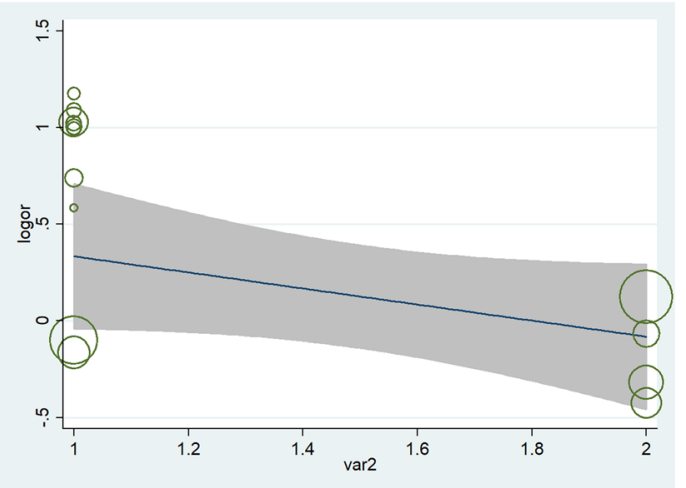

$E$

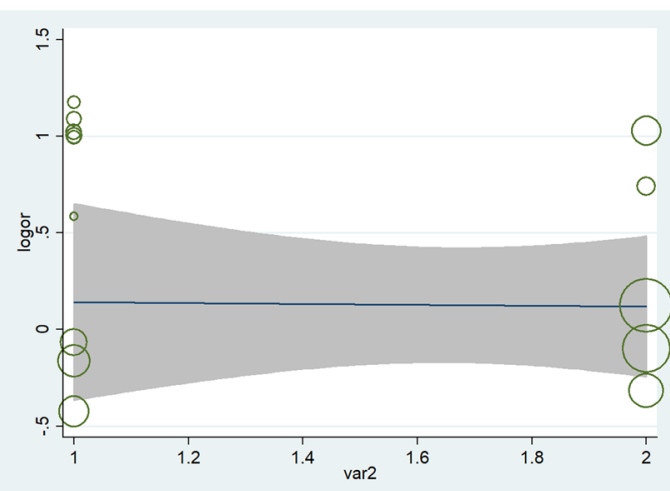

D

\section{Meta-regression}

REML estimate of between-study variance $\%$ residual variation due to heterogeneity Proportion of between-study variance explained with Knapp-Hartung modification

\begin{tabular}{r|rrrrrr}
\hline logor & Coef. & Std. Err. & $t$ & $p>|t|$ & \multicolumn{2}{l}{ [95\% Conf. Interval] } \\
\hline var2 & -.7816419 & .2918187 & -2.68 & 0.020 & -1.41746 & -.1458235 \\
- cons & 1.403228 & .4267959 & 3.29 & 0.006 & .4733198 & 2.333136 \\
\hline
\end{tabular}

$\mathrm{F}$

Meta-regression

REML estimate of between-study variance

$\%$ residual variation due to heterogeneity

Proportion of between-study variance explained

with Knapp-Hartung modification

\begin{tabular}{r|rrrrrr}
\hline logor & coef. & Std. Err. & $t$ & $p>|t|$ & \multicolumn{2}{l}{ [95\% Conf. Interval] } \\
\hline var2 & -.195165 & .3516835 & -0.55 & 0.589 & -.9614175 & .5710875 \\
_cons & .6495841 & .5334016 & 1.22 & 0.247 & -.5125982 & 1.811766
\end{tabular}

Fig. 7 Random-effect meta-regression of log odds ratio versus publication year (a), ethnicity (b), source of control (c) respectively in GD

MTTP activity and bile acid synthesis in patients with GD [48]. Stender et al. found that a PCSK9 genetic variant is associated with LDL-C level and influences the formation of GD [49]. In summary, we should thoroughly explore these partners of the $A P O B$ gene, as well as gene-gene interactions, in the development of GD in future studies. In addition, we tried to review the variants that are in linkage with the rs693 variant and identify probable exonic and functional variants as rs693 is a synonymous variant. Just only one paper reported by Xiao et al. was found about ischemic stroke not GD disease. They found that two blocks in $A P O B$ constructed by Block 1 (rs1042034, rs676210, rs693, rs673548) and
Block 2 (rs3791981, rs679899) in chromosome 2 with linkage disequilibrium [50].

There are some other limitations that should be addressed as well. First, further studies should focus on mixed and African populations, which were not represented in the current analysis. Second, because GD is a multi-factorial disease, gene-gene and gene-environment interactions should be considered and assessed. It is possible that specific environmental and lifestyle factors influence the associations between the $A P O B$ rs693 polymorphism and GD, including age, sex, diet, diabetes, smoking, familial history, surgical history, and hypertension. Third, whether patients with GD have other 
A

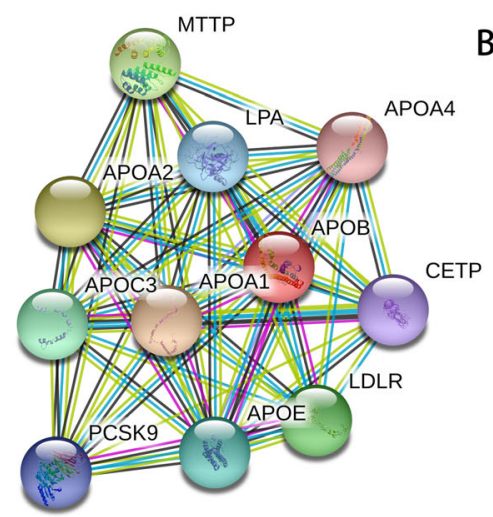

B Your Input:
Apolipoprotein B-100; Apolipoprotein B is a major protein constituent of chylomicrons (apo B-48), LDL (apo B-100) and VLDL
APOB (apo B-100). ApO B-100 functions as a recognition signal for the cellular binding and internalization of LDL particles by the apoB/E receptor; Apolipoproteins (4563 aa)

Predicted Functional Partners:

Q APOA1 Apolipoprotein A-t; Participates in the reverse transport of cholesterol from tissues to the liver for excretion by promoting chole. APOA2 Apolipoprotein A-ll: May stabilize HOL (high density lipoprotein) structure by its association with lipids, and affect the HDL meta O MTTP Microsomal triglyceride transfer protein large subunit; Catalyzes the transport of triglyceride, cholesteryl ester, and phospholipid.. - LDLR Low-density lipoprotein receptor; Binds LDL, the major cholesterol-carrying lipoprotein of plasma, and transports it into cells by. O APOC3 Apolipoprotein C-IIl; Component of triglyceride-rich very low density lipoproteins (VLDL) and high density lipoproteins (HDL) in p. - APOE Apolipoprotein E; Mediates the binding, internalization, and catabolism of lipoprotein particles. It can serve as a ligand for the L. O LPA Apolipoprotein(a); Apo(a) is the main constituent of lipoprotein(a) (Lp(a)). It has serine proteinase activity and is able of autopro - PCSK9 Proprotein convertase subtilisin/kexin type 9; Crucial player in the regulation of plasma cholesterol homeostasis. Binds to low-d. - CETP Cholesteryl ester transfer protein; IIvolved in the transfer of neutral lipids, including cholesteryl ester and triglyceride, among lip. - APOA4 Apolipoprotein A-IV; May have a role in chylomicrons and VLDL secretion and catabolism. Required for efficient activation of lip.

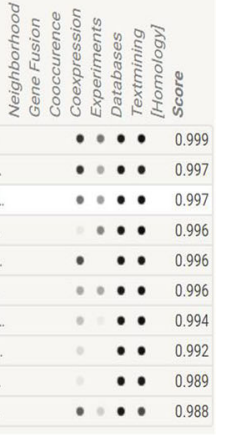

Fig. 8 Human $A P O B$ interactions network with other genes obtained from String server. At least 10 genes have been indicated to correlate with $A P O B$ gene. APOA1: apolipoprotein A-l; APOA2: apolipoprotein A-Il; MTTP: microsomal triglyceride transfer protein large subunit; LDLR: low-density lipoprotein receptor; APOC3: apolipoprotein C-III; APOE: apolipoprotein E; LPA: apolipoprotein (a); PCSK9: proprotein convertase subtilish/kexin type 9; CETP: cholesteryl ester transfer protein; APOA4: apolipoprotein A-IV

complications, such as liver dysfunction, dyslipidemia, and a history of GI obstruction was not reported in the included studies. Further comprehensive studies should include such information. Fourth, the type of stone composition was not distinguished, which should be analyzed separately and can result in more accurate assessments for prediction and treatment.

\section{Conclusions}

Our present meta-analysis suggests that the $A P O B$ rs693 polymorphism might be a powerful predictor of GD risk, which can serve as a detection method in clinics to provide early identification and caution patients with GD.

\section{Abbreviations}

GD: Gallbladder disease; APOB: Apolipoprotein B; HWE: Hardy-Weinberg equilibrium; OR: Odds ratio; 95\%Cl: 95\% Confidence interval

\section{Acknowledgements}

Not applicable.

\section{Authors' contributions}

HZ conceived and designed this study. LY searched for literature and collected the data. LY analyzed the data. LF wrote the paper. LF revised the whole paper. LF contributed to the analysis tools and performed the statistical analysis. The authors read and approved the final version of the manuscript.

\section{Funding}

None.

\section{Availability of data and materials}

All data generated or analyzed in this study are included in this published article and its supplementary information files.

\section{Declarations}

Ethics approval and consent to participate Not applicable.

\section{Consent for publication}

Not applicable.

\section{Competing interests}

The authors proclaim that they have no competing interests.

Received: 5 February 2021 Accepted: 13 April 2021

Published online: 03 May 2021

\section{References}

1. Di Ciaula A, Wang DQ, Portincasa P. Cholesterol cholelithiasis: part of a systemic metabolic disease, prone to primary prevention. Expert Rev Gastroenterol Hepatol. 2019;13(2):157-71.

2. Fiqueiredo JC, Haiman C, Porcel J, Buxbaum J, Stram D, Tambe N, Cozen W, Wilkens L, Le Marchand L, Setiawan WW. Sex and ethnic/racial-specific risk factors for gallbladder disease. BMC Gastroenterol. 2017;17(1):153.

3. Stinton LM, Shaffer EA. Epidemiology of gallbladder disease: cholelithiasis and cancer. Gut Liver. 2012:6(2):172-87.

4. Littlefield A, Lenahan C. Cholelithiasis: presentation and management. J Midwifery Women Health. 2019;64(3):289-97.

5. Shaffer EA. Gallstone disease: epidemiology of gallbladder stone disease. \&nbsp;Best practice research. Clin Gastroenterol. 2006;20(6):981-96.

6. Gurusamy KS, Davidson BR. Gallstones. BMJ. 2014;348:92669.

7. Gutt C, Schläfer S, Lammert F. The treatment of gallstone disease. Deutsches Arzteblatt Int. 2020;117(9):148-58.

8. Feingold KR, Grunfeld $C$, et al. Introduction to Lipids and Lipoproteins. In: Feingold KR, Anawalt B, Boyce A, Chrousos G, de Herder WW, Dungan K, Grossman A, Hershman JM, Hofland HJ, Kaltsas G, et al., editors. Endotext. Dartmouth: MDText.com, Inc.Copyright@ 2000-2020, MDText.com, Inc.; 2000.

9. Yang CY, Gu ZW, Weng SA, Kim TW, Chen SH, Pownall HJ, Sharp PM, Liu SW, Li WH, Gotto AM Jr, et al. Structure of apolipoprotein B-100 of human low density lipoproteins. Arteriosclerosis (Dallas Tex). 1989;9(1):96-108.

10. Benn M, Nordestgaard BG, Jensen JS, Grande P, Sillesen H, Tybjaerg-Hansen A. Polymorphism in APOB associated with increased low-density lipoprotein levels in both genders in the general population. J Clin Endocrinol Metab. 2005;90(10):5797-803.

11. Han T, Jiang Z, Suo G, Zhang S. Apolipoprotein B-100 gene Xba I polymorphism and cholesterol gallstone disease. Clin Genet. 2000;57(4):3048.

12. Rauscher $\mathrm{R}$, Ignatova Z. Timing during translation matters: synonymous mutations in human pathologies influence protein folding and function. Biochem Soc Transact. 2018:46(4):937-44.

13. Zheng S, Kim H, Verhaak RGW. Silent mutations make some noise. Cell. 2014;156(6):1129-31.

14. Supek F, Miñana B, Valcárcel J, Gabaldón T, Lehner B. Synonymous mutations frequently act as driver mutations in human cancers. Cell. 2014; 156(6):1324-35.

15. Báez S, Tsuchiya Y, Calvo A, Pruyas M, Nakamura K, Kiyohara C, Oyama M, Yamamoto M. Genetic variants involved in gallstone formation and 
capsaicin metabolism, and the risk of gallbladder cancer in Chilean women. World J Gastroenterol. 2010;16(3):372-8.

16. Dixit M, Srivastava A, Choudhuri G, Mittal B. Higher alleles of apolipoprotein B gene 3' VNTR: Risk for gallstone disease. Indian J Clin Biochem: IJCB. 2008; 23(2):123-9.

17. Juvonen T, Savolainen MJ, Kairaluoma MI, Lajunen LH, Humphries SE, Kesäniemi YA. Polymorphisms at the apoB, apoA-l, and cholesteryl ester transfer protein gene loci in patients with gallbladder disease. J Lipid Res. 1995;36(4):804-12

18. Kurzawski M, Juzyszyn Z, Modrzejewski A, Pawlik A, Wiatr M, Czerny B, Adamcewicz R, Droździk M. Apolipoprotein B (APOB) gene polymorphism in patients with gallbladder disease. Arch Med Res. 2007;38(3):360-3.

19. Rudzińska K, Bogacz A, Kotrych D, Wolski H, Majchrzycki M, SeremakMrozikiewicz A, Kosiński B, Czerny B. The APOB gene polymorphism in the pathogenesis of gallstone disease in pre- and postmenopausal women. Przeglad Menopauzalny = Menopause Rev. 2015;14(1):35-40.

20. Sánchez-Cuén J, Aguilar-Medina M, Arámbula-Meraz E, Romero-Navarro J, Granados J, Sicairos-Medina L, Ramos-Payán R. ApoB-100, ApoE and CYP7A1 gene polymorphisms in Mexican patients with cholesterol gallstone disease. World J Gastroenterol. 2010;16(37):4685-90.

21. Gu JP, Huang GY, Jiang ZH, Cai Q, Xu ZP, Ding JB, Xiao LJ, Cao YO, Shang J, Cai XX, et al. Relationship between apolipoprotein $B$ gene Xba I polymorphism and gallbladder stone disease. Chin J Hepatobiliary Surg. 2008;12(1):34-6.

22. Ji J, Liu Y, Yu Y, Shi JS. Relationshio between apolipoprotein B gene Xba I and EcoR I polymorphisms and cholelithiasis. Chin J Dig Surg. 2014;13(4): 291-4.

23. Jiang ZY, Han TQ, Suo GJ, Chen S, Zhu QM, He XW, Shen SQ, Gu JP, Huang $G Y$, Jiang $Z H$, et al. Study on the Apo B gene Xba I polymorphism in patients with gallbladder stones and its relation with serum lipids. J Surg Concepts Pract. 1999;4(1):18-21.

24. Suo GJ, Han TQ, Feng DX, Jiang ZH, Zhang SD. Association of polymorphisms of apolipoprotein $\mathrm{B}$ gene with cholesterol gallstone disease. Natl Med J China. 1999;79(9):673-5.

25. Tan YF, Yang S, Yu RB, Shen C, Ding WL, Zhou WM, Gong WD, Yao CL. Relationship among the Xba I and EcoR I locus polymorphisms of apolipoprotein B gene, serum lipid metabolism and gallstone disease. Natl Med J China. 2003;83(10):844-7.

26. Wei JB, Lin QY, Cheng NS, Zhang MY, Xiao LJ. Relationship between apolipoprotein B gene polymorphism and gallstone disease. Chin J Med Gentet. 2001;18(1):66-7.

27. Yang $X$, Yan $H$, Liu SH. Study on the relationship between apolipoproten $B$ gene polymorphism, blood lipid composition and gallstone. Xinjiang Med. 2009:39:39-41.

28. Yu J, Lin QY: Relationship among the Xba I locus polymorphisms of apolipoprotein B gene, serum lipid metabolism and gallstone disease. SiChuan University (Master's dissertation). 2005.

29. Niu C, Luo Z, Yu L, Yang Y, Chen Y, Luo X, Lai F, Song Y. Associations of the APOB rs693 and rs17240441 polymorphisms with plasma APOB and lipid levels: a meta-analysis. Lipids Health Dis. 2017;16(1):166.

30. Higgins JP, Thompson SG. Quantifying heterogeneity in a meta-analysis. Stat Med. 2002;21(11):1539-58.

31. Cheng JW, Cheng SW, Ma XY, Cai JP, Li Y, Lu GC, Wei RL: Myocilin polymorphisms and primary open-angle glaucoma: a systematic review and meta-analysis. PloS one.2012;7(9):e46632.

32. Zeng T, Guo FF, Zhang CL, Song FY, Zhao XL, Xie KQ: Roles of cytochrome P4502E1 gene polymorphisms and the risks of alcoholic liver disease: a meta-analysis. PloS one 2013;8(1):e54188.

33. Higgins JP, Thompson SG, Deeks JJ, Altman DG. Measuring inconsistency in meta-analyses. BMJ. 2003;327(7414):557-60.

34. DerSimonian R, Laird N. Meta-analysis in clinical trials. Contr Clin Trials. 1986; 7(3):177-88

35. Mantel N, Haenszel W. Statistical aspects of the analysis of data from retrospective studies of disease. J Natl Cancer Inst. 1959;22(4):719-48.

36. Mohammadi A, Azarnezhad A, Khanbabaei H, Izadpanah E, Abdollahzadeh $R$, Barreto GE, Sahebkar A. Vitamin D receptor genetic polymorphisms and the risk of multiple sclerosis: A systematic review and meta-analysis. Steroids. 2020;158:108615.

37. Napolioni $\mathrm{V}$. The relevance of checking population allele frequencies and Hardy-Weinberg Equilibrium in genetic association studies: the case of
SLC6A4 5-HTTLPR polymorphism in a Chinese Han irritable bowel syndrome association study. Immunol Lett . 2014;162(1 Pt A):276-8.

38. Hayashino $Y$, Noguchi $Y$, Fukui T. Systematic evaluation and comparison of statistical tests for publication bias. J Epidemiol. 2005;15(6):235-43.

39. Shao HB, Ren K, Gao SL, Zou JG, Mi YY, Zhang LF, Zuo L, Okada A, Yasui T. Human methionine synthase A2756G polymorphism increases susceptibility to prostate cancer. Aging. 2018;10(7):1776-88.

40. Moseley RH. Liver and biliary tract disorders. Curr Opin Gastroenterol. 2006; 22(3):193-7.

41. Jones MW, Weir CB, Ghassemzadeh S. Gallstones (Cholelithiasis). In: StatPearls. Treasure Island: StatPearls Publishing.Copyright @ 2020, StatPearls Publishing LLC.2020.

42. Gu Q, Zhou G, Xu T. Risk factors for gallstone disease in Shanghai: An observational study. Medicine. 2020;99(3):e18754.

43. Chuang SC, Hsi E, Wang SN, Yu ML, Lee KT, Juo SH. Polymorphism at the mucin-like protocadherin gene influences susceptibility to gallstone disease. Clin Chim Acta. 2011:412(23-24):2089-93.

44. Katsika D, Magnusson P, Krawczyk M, Grünhage F, Lichtenstein P, Einarsson C, Lammert F, Marschall HU. Gallstone disease in Swedish twins: risk is associated with ABCG8 D19H genotype. J Intern Med. 2010;268(3):279-85.

45. Li L, Qiao X, Wang X, Liu D, Xue Q, Han L, Dai F, Ma G, Yang Z, Zhang T, et al: The association between apolipoprotein $E$ and gallstone disease: an updated meta-analysis. BMC Med Genet.2019;20(1):109.

46. Dixit M, Choudhuri G, Saxena R, Mittal B. Association of apolipoprotein A1C3 gene cluster polymorphisms with gallstone disease. Can J Gastroenterol= J Canadien de Gastroenterologie. 2007;21(9):569-75.

47. Saraç S, Atamer A, Atamer Y, Can AS, Bilici A, Taçyildiz I, Koçyiğit Y, Yenice N. Leptin levels and lipoprotein profiles in patients with cholelithiasis. J Int Med Res. 2015:43(3):385-92.

48. Castro J, Amigo L, Miquel JF, Gälman C, Crovari F, Raddatz A, Zanlungo S, Jalil R, Rudling M, Nervi F. Increased activity of hepatic microsomal triglyceride transfer protein and bile acid synthesis in gallstone disease. Hepatology. 2007;45(5):1261-6.

49. Stender S, Frikke-Schmidt R, Benn M, Nordestgaard BG, Tybjærg-Hansen A. Low-density lipoprotein cholesterol and risk of gallstone disease: a Mendelian randomization study and meta-analyses. J Hepatol. 2013;58(1): 126-33.

50. Xiao R, Sun S, Zhang J, Ouyang Y, Zhang N, Yang M, Jin T, Xia Y. Association analysis of APO gene polymorphisms with ischemic stroke risk: a casecontrol study in a Chinese Han population. Oncotarget. 2017;8(36):60496503.

\section{Publisher's Note}

Springer Nature remains neutral with regard to jurisdictional claims in published maps and institutional affiliations.

Ready to submit your research? Choose BMC and benefit from:

- fast, convenient online submission

- thorough peer review by experienced researchers in your field

- rapid publication on acceptance

- support for research data, including large and complex data types

- gold Open Access which fosters wider collaboration and increased citations

- maximum visibility for your research: over $100 \mathrm{M}$ website views per year

At BMC, research is always in progress.

Learn more biomedcentral.com/submissions 